\title{
DESEMPENHO DE UMA SEMEADORA-ADUBADORA PARA PLANTIO DIRETO, EM DOIS SOLOS COM DIFERENTES TIPOS DE COBERTURA VEGETAL ${ }^{1}$
}

\author{
MILSON LOPES DE OLIVEIRA ${ }^{2}$, LUCIANO BAIÃO VIEIRA ${ }^{3}$, EVANDRO CHARTUNI MANTOVANI ${ }^{4}$, \\ CAETANO MARCIANO DE SOUZA ${ }^{5}$ e GUTEMBERG PEREIRADIAS ${ }^{3}$
}

\begin{abstract}
RESUMO - O desempenho operacional de uma semeadora-adubadora de plantio direto, versão soja e milho, foi avaliado em um Podzólico Vermelho-Amarelo câmbico, fase terraço, e um Latossolo Vermelho-Amarelo, da Zona da Mata de Minas Gerais. A máquina foi testada em três tipos de cobertura do solo e em duas velocidades de trabalho. Por ocasião do plantio, foram avaliados a patinagem do trator e da semeadora-adubadora, o consumo de combustível e a potência exigida, a distribuição de fertilizante e o nível de danos às sementes. Depois do plantio, foram avaliados o número de sementes distribuídas, o estande final, a profundidade de plantio e a distribuição longitudinal da semente. A uniformidade de distribuição longitudinal foi avaliada pela porcentagem de espaçamentos aceitáveis, distribuição dupla e falhas na distribuição, e pelo coeficiente de variação dos espaçamentos entre sementes. A demanda de potência foi maior no Podzólico, por sua maior densidade e resistência à penetração. Independentemente do tratamento, o número de sementes distribuídas e o estande final não apresentaram diferenças significativas. As sementes distribuídas não tiveram sua qualidade afetada pelos dosadores da máquina. A análise de variância não indicou diferença significativa entre os porcentuais de espaçamentos aceitáveis, a distribuição dupla e as falhas.
\end{abstract}

Termos para indexação: mecanização, teste do equipamento, desempenho da máquina, maquinaria agrícola.

\section{PERFORMANCE OF A NO-TILLAGE SEEDER, IN TWO SOILS WITH DIFFERENT TYPES OF VEGETABLE COVERAGES}

\begin{abstract}
The performance of a no-tillage seeder, version soybean and corn was evaluated under two classes of soil, a cambic Red-Yellow Podzolic terrace phase and a Red-Yellow Latosol, at Zona da Mata, MG. The machine was tested under three different vegetable coverages in two work speeds. During test, tractor and planter slipping, fuel consumption and the power required by the machine, distribution fertilizer, and seeds damage were evaluated. After planting, the number of seeds by hectare, final stand, planting depth and seed longitudinal distribution, were also evaluated. The uniformity of longitudinal distribution was measured for percentage of admissible spacing, pair distribution, failures on distribution and by coefficient variation of seed spacing. The demand of power was higher on podzolic, due to its higher density and resistance to penetration. Regardless of the type of treatment, the number of seeds distributed and the final stand obtained showed no significant difference and the depth average obtained in the test was close to the values foreseen in the control. The seeds distributed were not affected by dosage mechanism. The analysis of variance indicated no significant variation between the values of admissible spacing, the pair distribution and failures.
\end{abstract}

Index terms: mechanization, equipment testing, equipment performance, agricultural machinery.

1 Aceito para publicação em 13 de maio de 1999

${ }^{2}$ Eng. Agríc., M.Sc., Dep. de Engenharia Agrícola, Universidade Federal de Viçosa (UFV), CEP 36570-000 Viçosa, MG E-mail: mlopes@homenet.com.br

${ }^{3}$ Eng. Agrôn., D.Sc., Dep. de Engenharia Agrícola, UFV.

${ }^{4}$ Eng. Agrôn., Ph.D., Embrapa-Centro Nacional de Pesquisa de Milho e Sorgo (CNPMS), Rod. MG 424, km 65, Caixa Postal 151, CEP 35701-970 Sete Lagoas, MG

${ }^{5}$ Eng. Agrôn., D.Sc., Dep. de Fitotecnia, UFV.

\section{INTRODUÇÃO}

Na Zona da Mata de Minas Gerais, grande parte do relevo é acidentado e ocorrem chuvas de grande intensidade no verão, verificando-se, com freqüência, problemas pertinentes à conservação do solo $\mathrm{e}$ da água, sendo a erosão um dos mais preocupantes. Perdas de solo são comuns, por exemplo, na cultura 
do milho, que é o principal cereal cultivado em termos de área, e o segundo em termos de valor bruto da produção. Algumas justificativas para esse fato estão relacionadas com a adoção de métodos de cultivo que resultam na desagregação e exposição do solo aos agentes intempéricos.

Em regiões com problemas similares, como a Região Sul do Brasil, uma alternativa encontrada para minimizar a perda de solo foi o emprego do plantio direto. A introdução do plantio direto na Zona da Mata de Minas Gerais pode resultar em avanços no manejo e na conservação do solo e da água. Entretanto, existem algumas dúvidas quanto aos resultados diante de algumas peculiaridades regionais dos solos, topografia e áreas de cultivo, dentre outras.

Os aspectos mais relevantes para o sucesso da lavoura no plantio direto estão relacionados com o desempenho da semeadora-adubadora no que se refere ao corte eficiente dos restos culturais, à abertura do sulco e à colocação da semente e do fertilizante em profundidades corretas e em contato com $o$ solo. Também é importante que as máquinas apresentem adequada regularidade, com distribuição precisa de sementes e fertilizante (Embrapa, 1994).

Vários fatores afetam a operação de semeadura, podendo estes estar relacionados à semente, ao solo, à máquina, ao clima e ao operador. Com relação ao material propagativo, merecem destaque a quantidade, a uniformidade de distribuição, a profundidade de colocação e a cobertura das sementes. Já a influência da máquina se dá pelo tipo de mecanismo dosador e sua forma de acionamento, pelo tipo de sulcador e pelo tipo de mecanismo de cobertura da semente (Balastreire, 1987).

A precisão de plantio é importante fator na eficiência de uso da terra, pois todo o processo produtivo é potencialmente dependente dos resultados obtidos na semeadura. Mantovani et al. (1992) avaliaram nove semeadoras de milho e concluíram que, de maneira geral, a distribuição longitudinal de sementes era irregular e fora dos limites aceitáveis, tendendo a se tornar mais irregular à medida que a velocidade de avanço aumentava. Estudos realizados por Delafosse (1986) mostraram que a falta de regularidade de espaçamento entre plantas pode resultar em perdas superiores a $15 \%$ na cultura do milho.
Em razão disto, este trabalho objetivou avaliar o desempenho operacional de uma semeadoraadubadora para plantio direto nas duas classes de solo predominantes na região.

\section{MATERIAL E MÉTODOS}

Os testes foram realizados no ano agrícola 1996/97, nos campos experimentais da Universidade Federal de Viçosa, MG, de altitude entre 600 a $700 \mathrm{~m}$, com uma precipitação média anual de 1.300 a $1.400 \mathrm{~mm}$, concentrada principalmente, no período de outubro a março, com média anual de umidade relativa do ar de $80 \%$ a $85 \%$ e uma temperatura média anual de $19^{\circ} \mathrm{C}$

Utilizou-se como fonte de potência, nos testes experimentais, um trator da marca Massey Ferguson, modelo $2654 \mathrm{X} 2$ TDA, com potência máxima de $48 \mathrm{~kW}$ no motor a $2.000 \mathrm{rpm}$.A semeadora-adubadora da marca Vence Tudo, modelo S.A. 13.500, versão soja e milho (três linhas de plantio de milho), foi selecionada para os testes em virtude de sua rusticidade, estrutura compacta (3,02 $\mathrm{m}$ de largura), peso reduzido (745 kg com os depósitos vazios), mecanismos simples de funcionamento, constituído por conjunto rompedor e distribuidor de fertilizante do tipo disco de corte mais facão, conjunto rompedor e distribuidor de sementes do tipo disco duplo defasado, dosador de sementes mecânico do tipo disco horizontal perfurado e dosador de adubo do tipo rotor dentado acionados por pneus de tração, por ser acoplada ao engate de três pontos e apresentar um porte adequado para atender às necessidades das propriedades da região da Zona da Mata.

Os testes foram realizados em um solo Podzólico Vermelho-Amarelo câmbico, fase terraço (PVc), plano, e um Latossolo Vermelho-Amarelo (LV) com declividade média de $11 \%$. Ambas as áreas encontravam-se cobertas com vegetação espontânea, predominando a losna brava, a marmelada e o picão-preto, no Podzólico; o capim-amargoso, o capim-gordura e o capim-pernambuco, no Latossolo.

Cada unidade experimental consistiu de uma área de $300 \mathrm{~m}^{2}$, sendo $50 \mathrm{~m}$ de comprimento e $6 \mathrm{~m}$ de largura, o suficiente para avaliar o equipamento em percurso de ida $\mathrm{e}$ volta. O delineamento utilizado foi o inteiramente casualizado, sendo os tratamentos obtidos pela combinação de duas velocidades com três tipos de cobertura, totalizando seis tratamentos, com três repetições, em cada solo.

Antes dos testes, foi feita a caracterização física do solo, envolvendo: resistência do solo à penetração, de acordo com a norma ASAE S.313.2 (American Society of Agricultural Engineers, 1990), teor de umidade, densidade 
de partículas, densidade do solo, porosidade total, composição granulométrica, bem como a análise química de rotina do solo para fins de adequação química das unidades experimentais (Embrapa, 1979).

A máquina foi testada em três tipos de resíduos vegetais secos: milho (Zea mays L.), labe-labe (Dolichos lab $l a b$ L.) e vegetação espontânea, sendo as duas primeiras cultivadas com o objetivo de produzir os resíduos. $\mathrm{Na}$ época de floração das culturas do milho e do labe-labe, todas as unidades experimentais foram dessecadas com herbicida, e roçadas, para evitar a possibilidade de infestação da área durante os testes. O nível de cobertura do solo foi determinado na época do plantio, mediante a coleta de palha em uma área de $1 \mathrm{~m}^{2}$, com cinco repetições por unidade experimental (Embrapa, 1994).

A semeadora-adubadora foi testada em duas velocidades, ou seja, 5 e $7 \mathrm{~km} / \mathrm{hora}$, que correspondem no trator à 5a marcha a $1.600 \mathrm{rpm}$ e $7 \stackrel{\text { a }}{ }$ marcha a $1.500 \mathrm{rpm}$, respectivamente.

Antes de serem realizados os testes de avaliação de desempenho, a semeadora-adubadora foi regulada por técnicos do fabricante, visando ao plantio da cultura do milho, com espaçamento de $0,9 \mathrm{~m}$ entre linhas, profundidade de $6 \mathrm{~cm}$ e uma densidade de 6,3 plantas por metro linear para se obter um estande aproximado de 70.000 plantas $\mathrm{ha}^{-1}$. A semente utilizada no plantio foi o híbrido BR 201, peneira 20 longo e foram distribuídos $425 \mathrm{~kg} \mathrm{ha}^{-1}$ de fertilizante granulado da fórmula comercial 4-14-8

No teste de desempenho, por ocasião do plantio, foram avaliados os seguintes aspectos: patinagem do trator $\mathrm{e}$ da semeadora, consumo de combustível, potência exigida pela máquina, distribuição do fertilizante e nível de danos às sementes. Vinte dias depois do plantio, a faixa situada nos $30 \mathrm{~m}$ centrais da unidade experimental foi utilizada para avaliar o número de sementes distribuídas, o estande final, a profundidade de plantio e a distribuição longitudinal de sementes.

A patinagem das rodas motrizes foi determinada pela relação entre a velocidade real do trator em regime de trabalho e a velocidade do trator sem carga, conforme norma ASAE EP496 (American Society of Agricultural Engineers, 1990). A patinagem da roda de acionamento dos dosadores de semente foi medida com um tacômetro analógico, comparando-se o número de rotações da roda sem carga com o obtido sob regime normal de trabalho.

O consumo de combustível foi determinado por meio de um fluxímetro, graduado em $\mathrm{mL}$. De posse dos dados de consumo de combustível, calculou-se o consumo horário e o consumo por hectare. Para determinação da potência demandada pelo conjunto, o trator foi equipado com um tacômetro digital na tomada de potência (TDP), para re- gistrar o número de rotações por unidade de tempo. Empregando-se o número de rotações na TDP, obteve-se o número de rotações do motor por uma equação de regressão $\mathrm{Y}=32,027 \mathrm{X}-8,7542$, onde: $\mathrm{X}$ é a rotação média registrada na TDP e Y é a rotação do motor em rpm.

Utilizando-se os dados de consumo horário de combustível e de rotação do motor, obteve-se a potência demandada, através das curvas de calibração do trator (Mantovani et al., 1992). Foram usadas as curvas de um trator novo, uma vez que o trator usado encontrava-se em bom estado de conservação, com aproximadamente 2.000 horas de uso

A avaliação da distribuição do fertilizante foi realizada mediante coleta do material, ao longo do comprimento da unidade experimental, durante o percurso de ida e volta, determinando-se a quantidade de fertilizante por hectare $\mathrm{e}$ a uniformidade de distribuição transversal e longitudinal (Mantovani et al., 1992).

Foram recolhidas amostras no depósito de sementes e na saída do mecanismo dosador da máquina, com as quais realizaram-se testes de germinação padrão e de envelhecimento precoce, com vistas a avaliar o nível de danos mecânicos à semente causados pela máquina.

O número de sementes foi determinado em função da distribuição longitudinal, considerando-se também as sementes não germinadas, correspondendo, portanto, ao número de sementes distribuídas por hectare. $\mathrm{O}$ estande final, correspondente ao número de plantas por hectare, foi determinado tomando-se por base os resultados de distribuição longitudinal, pela contagem das plântulas que emergiram (Mantovani et al., 1992).

Para cada unidade experimental, foram sorteadas três fileiras de milho, uma em cada unidade de plantio da semeadora, e foi definida ao acaso, e de forma intercalada, uma faixa de $10 \mathrm{~m}$, onde as plântulas foram cortadas na superfície e os mesocótilos com as sementes removidas do solo. Mediu-se com paquímetro a porção entre a parte inferior da semente e a superfície do solo, obtendo-se a profundidade de plantio (Mantovani et al., 1992)

$\mathrm{Na}$ avaliação da distribuição longitudinal, as distâncias entre plantas, bem como entre plantas e sementes não germinadas foram medidas com régua. A porcentagem de espaçamentos aceitáveis foi obtida de acordo com as normas da ABNT, citadas por Kurachi et al. (1989), considerando-se como aceitáveis os espaçamentos situados entre 0,5 a 1,5 vez o espaçamento médio esperado. Abaixo do limite inferior, foi admitido como sementes duplas e, acima do limite superior do intervalo, considerou-se como falha na distribuição.

De posse dos dados experimentais, procedeu-se à análise de variância dos parâmetros estudados, verificando-se 
a significância de seus efeitos. Para avaliar o número de sementes, o estande final, a profundidade de plantio e a uniformidade de distribuição longitudinal das sementes, em cada tratamento, foram calculadas as médias e os coeficientes de variação dos valores obtidos.

\section{RESULTADOS E DISCUSSÃO}

Os valores de densidade do solo, densidade de partículas, porosidade, índice de cone e umidade atual, são apresentados na Tabela 1. Não se verificou diferença significativa entre as características físicas, exceto para o índice de cone no Podzólico, cujos valores obtidos foram maiores na cobertura de labe-labe. O índice de cone médio obtido para os solos testados apresentou valores mais altos no Podzólico, provavelmente devido a sua maior densidade.

A Tabela 2 apresenta os valores de massa seca da cobertura vegetal e os valores médios da patinagem das rodas motrizes do trator e da roda de acionamento dos dosadores de semente, nas duas classes de solo. No Podzólico, foi observada diferença significativa na quantidade de cobertura do solo, tendo o labe-labe produzido a menor e o milho a maior quantidade de massa seca. Os dois solos apresentaram pequena diferença entre a quantidade de cobertura; entretanto, o valor médio da massa seca obtida nas coberturas de milho e labe-labe foram maiores no Podzólico, provavelmente por suas melhores condições de fertilidade. Não se verificou o mesmo comportamento com relação à vegetação espontânea, que produziu maior quantidade de massa seca no Latossolo. Provavelmente, isso ocorreu porque este solo encontrava-se em pousio por um maior período de tempo do que o Podzólico.

Pela análise de variância, não se verificou diferença significativa na patinagem do rodado do trator; todavia, foi obtido um índice médio de patinagem maior na velocidade de $7 \mathrm{~km}$ hora $^{-1}$ no solo Podzólico, e um índice médio menor no Latossolo. Esse comportamento contrário pode ter ocorrido devido à menor densidade e resistência do solo à penetração, possibilitando o aprofundamento da roda, aumentando a resistência ao seu deslocamento. A patinagem média no Podzólico foi maior que no Latossolo, por sua maior densidade do solo,

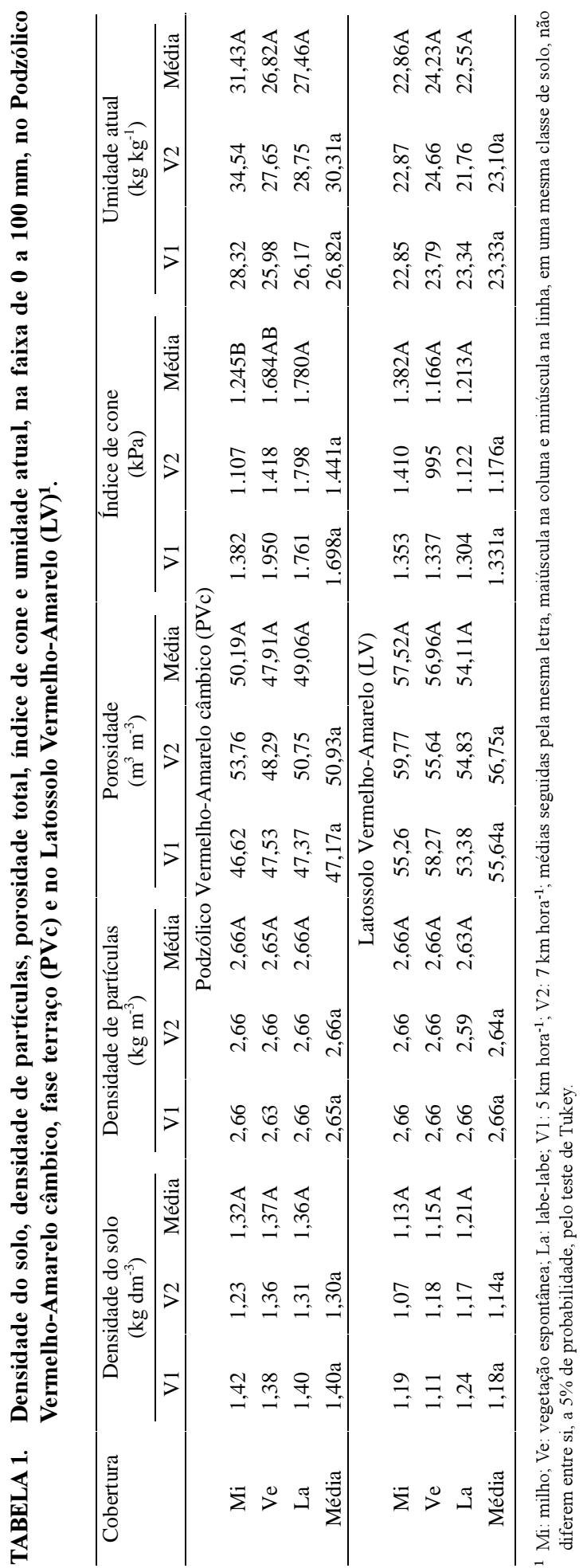


implicando maior demanda de força para rompimento do solo. Como o solo não foi mobilizado, podese considerá-lo como firme, mas mesmo assim os valores de patinagem foram muito baixos. Os motivos que podem ter levado a esses resultados talvez tenham sido: ou a fonte de potência superdimensionada, ou o excesso de lastros no trator.

A análise de variância não indicou diferença significativa na patinagem da roda semeadora, ao se variar a velocidade de trabalho e o tipo de cobertura no Podzólico. Entretanto, as maiores patinagens foram obtidas na maior velocidade, exceto no tocante à cobertura de milho. É possível que esse efeito contrário tenha sido decorrente do grande volume de palha nesse tratamento. No Latossolo, foram encontradas diferenças significativas apenas quanto à variação de velocidade, com valores mais altos de patinagem na menor velocidade. A patinagem obtida no Latossolo foi maior que a do Podzólico em todos os tratamentos.

Na Tabela 3 encontram-se os valores médios do consumo horário de combustível, do consumo por hectare e da potência demandada pela máquina em cada tratamento. Tanto no Podzólico, quanto no Latossolo, foram verificadas diferenças significativas no consumo horário ao variar a velocidade, não apresentando diferenças ao variar a condição de superfície. Em ambos solos, o consumo por hectare apresentou diferenças significativas somente ao se variar a velocidade, sendo observado maior consumo na velocidade de $5 \mathrm{~km}$ hora $^{-1}$, em todos os tratamentos. O maior consumo em $\mathrm{L} \mathrm{ha}^{-1}$, na velocidade mais baixa nos dois solos se justifica pela redução da capacidade operacional do conjunto, em relação à maior velocidade. A análise de variância dos valores obtidos nos dois solos estudados indicou diferenças na demanda de potência ao variar a velocidade, exigindo maior potência na maior velocidade de trabalho; entretanto, a condição de superfície não interferiu significativamente. Sendo a potência produto da força de tração pela velocidade, então é coerente que ao aumentar a velocidade tenha ocorrido um aumento na potência demandada. Os valores médios de potência demandada em cada tratamento no Podzólico foram superiores aos do Latossolo, devido a sua maior densidade e resistência à pene- 


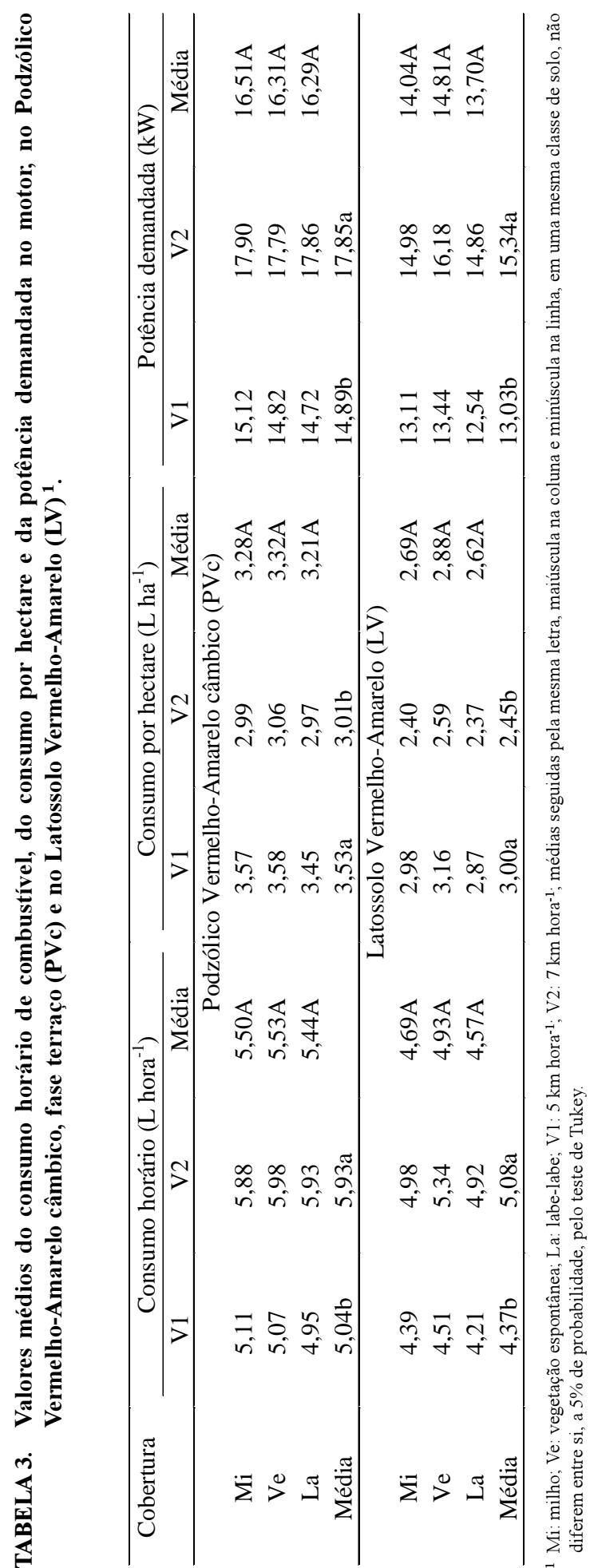

tração. Constatou-se, ainda, que a potência demandada pela máquina foi menor que os valores indicados no catálogo do fabricante.

Não se verificou diferença significativa na uniformidade de distribuição transversal de fertilizante, ao se compararem as quantidades distribuídas para cada unidade de plantio, e foi obtido um coeficiente de variação de $2,60 \%$ e $2,82 \%$ para 5 e $7 \mathrm{~km} \mathrm{hora}^{-1}$, respectivamente (Tabela 4).

Os resultados da análise de qualidade das sementes utilizadas nos dois solos são apresentados na Tabela 5, e mostram que houve diferença no poder germinativo e no vigor das sementes que passaram pelos dosadores, em relação àquelas retiradas do depósito, mas essa diferença não foi significativa. As sementes utilizadas no Latossolo apresentaram maior coeficiente de variação entre os dados de vigor do que as utilizadas no Podzólico. Os índices de danos podem ter sido influenciados pelo emprego de grafite misturado às sementes, ou, ainda, pelo fato de a máquina apresentar discos dosadores confeccionados em náilon, que minimizam o atrito sobre as sementes.

A Tabela 6 apresenta os dados do número de sementes, estande final, profundidade média de plantio e distribuição longitudinal, envolvendo: espaçamentos aceitáveis, duplos e falhas, espaçamento médio e coeficiente de variação dos espaçamentos entre sementes, para cada tratamento, nos dois solos estudados. No Podzólico Vermelho-Amarelo câmbico, não foi possível avaliar os parâmetros enumerados nos mesmos tratamentos empregados no Latossolo Vermelho-Amarelo. Nesse solo foi feita a semeadura utilizando-se nos testes apenas unidades experimentais cobertas com vegetação espontânea, as quais foram semeadas nas velocidades de 5 e $7 \mathrm{~km}$ hora ${ }^{-1}$, com três repetições para cada velocidade.

No Latossolo não se verificou diferença significativa no número de sementes e estande final observados, ao se alterar a velocidade e o tipo de cobertura, exceto a de milho. Entretanto, foram encontradas pequenas diferenças ao variar a velocidade de plantio, com os menores valores na maior velocidade de avanço, em conformidade com o proposto por Delafosse (1986). O resultado encontrado na cobertura de milho pode ser atribuído a problemas na 
coleta de dados, dada a dificuldade de localização das sementes não germinadas, ou, ainda, é possível que a cobertura tenha interferido no controle de profundidade, afetando a germinação das sementes. No Podzólico foi observado comportamento semelhante.

O coeficiente de variação médio do número de sementes no Latossolo foi de $10,01 \%$ e $5,04 \%$ no Podzólico, ficando abaixo do valor médio de $12,22 \%$ obtido por Mantovani et al. (1992). O estande final médio obtido no Latossolo foi $24,65 \%$ e no Podzólico $5,02 \%$ menor que o número de sementes distribuídas. A diferença verificada nos dois solos pode ter ocorrido devido ao baixo poder germinativo das sementes utilizadas no Latossolo, cujo índice de germinação médio foi de $83 \%$. Isso também pode justificar a diferença entre os valores do coeficiente de variação para o estande final de $20,71 \%$ no Latossolo e $6,56 \%$ no Podzólico.

No Latossolo não foi verificada diferença significativa entre tratamentos com relação à profundidade de plantio; contudo, o tratamento constituído por vegetação espontânea sob a velocidade de $5 \mathrm{~km}$ hora $^{-1}$ apresentou a menor profundidade; conseqüentemente, foi o que possibilitou o maior estande final entre os tratamentos. Os coeficientes de variação da profundidade de $8,57 \%$ nos tratamentos estudados no Latossolo, e 10,39\% no Podzólico, foram menores que os valores obtidos por Mantovani et al. (1992). No Latossolo, as profundidades de todos os tratamentos foram superiores aos valores esperados, sendo a profundidade média $11 \%$ maior que a estabelecida pela regulagem. Essa variação pode ser atribuída à menor resistência deste solo à penetração dos sulcadores, uma vez que foi mantida a mesma regulagem de profundidade feita em relação ao Podzólico. No Podzólico, a profundidade média foi praticamente igual ao valor estabelecido na regulagem, sendo o valor obtido na velocidade mais baixa 2,0\% menor, e 2,83\% maior, do que o valor esperado na velocidade mais alta.

No Latossolo a análise de variância não mostrou diferença significativa entre os valores médios das porcentagens de espaçamentos aceitáveis, de duplos e falhas, o que indica que a velocidade e o tipo de cobertura não afetaram a distribuição longitudinal das sementes. Resultados similares foram obtidos no Podzólico, onde a velocidade de avanço não afetou a distribuição longitudinal das sementes, contrariando os resultados obtidos por Pacheco (1994). Os coeficientes de variação dos espaçamentos aceitáveis foram $7,41 \%$ no Latossolo e $7,84 \%$ no Podzólico. Mantovani et al. (1992) encontraram coeficientes de variação variando de $18 \%$ a $32 \%$.

TABELA 4. Resultados da distribuição do fertilizante, para cada unidade de plantio, em função da velocidade de trabalho.

\begin{tabular}{|c|c|c|c|c|c|c|}
\hline \multirow{2}{*}{$\begin{array}{l}\text { Velocidade } \\
\left(\mathrm{km} \text { hora }^{-1}\right)\end{array}$} & \multicolumn{4}{|c|}{ Quantidade de fertilizante $\left(\mathrm{kg} \mathrm{ha}^{-1}\right)$} & \multirow{2}{*}{$\begin{array}{l}\text { Previsto } \\
\left(\mathrm{kg} \mathrm{ha}^{-1}\right)\end{array}$} & \multirow{2}{*}{$\begin{array}{c}\text { Coef. de } \\
\text { variação }(\%)\end{array}$} \\
\hline & Linha 1 & Linha 2 & Linha 3 & Média & & \\
\hline 5 & 460,98 & 438,19 & 445,39 & 448,19 & 425,00 & 2,60 \\
\hline 7 & 442,72 & 422,67 & 445,09 & 436,83 & 425,00 & 2,82 \\
\hline
\end{tabular}

TABELA 5. Poder germinativo e vigor das sementes coletadas no depósito e na saída dos dosadores da máquina, nas duas velocidades, nos dois solos estudados.

\begin{tabular}{|c|c|c|c|c|c|c|}
\hline Teste & $5 \mathrm{~km} \mathrm{hora}^{-1}$ & $7 \mathrm{~km} \mathrm{hora}^{-1}$ & Média & $\begin{array}{c}\text { Coef. de } \\
\text { variação }(\%)\end{array}$ & Depósito & $\begin{array}{c}\text { Coef. de } \\
\text { variação (\%) }\end{array}$ \\
\hline \multicolumn{7}{|c|}{ Podzólico Vermelho-Amarelo câmbico (PVc) } \\
\hline Germinação (\%) & 88,00 & 93,00 & 90,50 & 3,33 & 94,50 & 5,00 \\
\hline Vigor $(\%)$ & 44,00 & 52,00 & 48,00 & 14,03 & 59,00 & 16,78 \\
\hline \multicolumn{7}{|c|}{ Latossolo Vermelho Amarelo (LV) } \\
\hline Germinação (\%) & 82,67 & 81,0 & 81,84 & 0,10 & 83,00 & 5,74 \\
\hline Vigor $(\%)$ & 51,00 & 47,00 & 49,00 & 27,49 & 62,00 & 7,45 \\
\hline
\end{tabular}


TABELA 6. Número de sementes por hectare, estande final, profundidade de plantio, porcentagem de espaçamentos aceitáveis, espaçamento médio e coeficientes de variação dos espaçamentos entre sementes, nos dois solos ${ }^{1}$.

\begin{tabular}{|c|c|c|c|c|c|c|}
\hline \multicolumn{3}{|c|}{ Podzólico Vermelho-Amarelo câmbico } & \multicolumn{4}{|c|}{ Latossolo Vermelho-Amarelo } \\
\hline V1 & $\mathrm{V} 2$ & Média & Cobertura & $\mathrm{V} 1$ & V2 & Média \\
\hline \multicolumn{7}{|c|}{ Número de sementes por hectare } \\
\hline \multirow[t]{4}{*}{$69.808 \mathrm{~A}$} & $65.424 \mathrm{~A}$ & 67.616 & $\mathrm{Mi}$ & 61.691 & 62.551 & $62.121 \mathrm{~A}$ \\
\hline & & & $\mathrm{Ve}$ & 66.839 & 62.994 & $64.917 \mathrm{~A}$ \\
\hline & & & $\mathrm{La}$ & 64.921 & 62.379 & \\
\hline & & & Média & $64.484 \mathrm{a}$ & $62.641 \mathrm{a}$ & \\
\hline \multicolumn{7}{|c|}{ Estande final (plantas ha $\left.{ }^{-1}\right)$} \\
\hline \multirow[t]{4}{*}{$65.734 \mathrm{~A}$} & $62.709 \mathrm{~A}$ & 64.222 & $\mathrm{Mi}$ & 45.177 & 48.636 & $46.907 \mathrm{~A}$ \\
\hline & & & $\mathrm{Ve}$ & 53.080 & 49.132 & $51.106 \mathrm{~A}$ \\
\hline & & & $\mathrm{La}$ & 49.502 & 41.848 & $45.675 \mathrm{~A}$ \\
\hline & & & Média & $49.253 \mathrm{a}$ & $46.539 \mathrm{a}$ & \\
\hline \multirow{5}{*}{$5,88 \mathrm{~A}$} & & \multicolumn{3}{|c|}{ Profundidade de plantio $(\mathrm{cm})$} & & \\
\hline & $6,17 \mathrm{~A}$ & 6,02 & $\mathrm{Mi}$ & 6,87 & 6,81 & $6,84 \mathrm{~A}$ \\
\hline & & & $\mathrm{Ve}$ & 6,30 & 6,66 & $6,48 \mathrm{~A}$ \\
\hline & & & $\mathrm{La}$ & 6,96 & 6,73 & $6,85 \mathrm{~A}$ \\
\hline & & & Média & $6,71 \mathrm{a}$ & $6,73 \mathrm{a}$ & \\
\hline \multirow{5}{*}{$75,90 \mathrm{~A}$} & & \multicolumn{3}{|c|}{ Espaçamentos aceitáveis (\%) } & & \\
\hline & $67,90 \mathrm{~A}$ & 71,90 & $\mathrm{Mi}$ & 78,91 & 74,52 & $76,72 \mathrm{~A}$ \\
\hline & & & $\mathrm{Ve}$ & 82,28 & 73,75 & $78,02 \mathrm{~A}$ \\
\hline & & & $\mathrm{La}$ & 78,66 & 77,21 & $77,94 \mathrm{~A}$ \\
\hline & & & Média & $79,95 \mathrm{a}$ & $75,16 \mathrm{a}$ & \\
\hline \multirow{5}{*}{$15,94 \mathrm{~A}$} & & \multicolumn{3}{|c|}{ Espaçamento médio $(\mathrm{cm})$} & & \\
\hline & $17,01 \mathrm{~A}$ & 16,48 & $\mathrm{Mi}$ & 17,78 & 16,67 & $17,23 \mathrm{~A}$ \\
\hline & & & $\mathrm{Ve}$ & 17,68 & 17,37 & $17,53 \mathrm{~A}$ \\
\hline & & & $\mathrm{La}$ & 17,96 & 17,65 & $17,81 \mathrm{~A}$ \\
\hline & & & Média & $17,81 \mathrm{a}$ & $17,23 \mathrm{a}$ & \\
\hline \multirow{5}{*}{$11,50 \mathrm{~A}$} & & \multicolumn{3}{|c|}{ CV do espaçamento médio (\%) } & & \\
\hline & $4,53 \mathrm{~A}$ & 8,02 & $\mathrm{Mi}$ & 11,53 & 7,28 & $9,41 \mathrm{~A}$ \\
\hline & & & $\mathrm{Ve}$ & 11,63 & 7,23 & $9,43 \mathrm{~A}$ \\
\hline & & & $\mathrm{La}$ & 6,66 & 5,89 & $6,28 \mathrm{~A}$ \\
\hline & & & Média & $9,94 \mathrm{a}$ & $6,80 \mathrm{a}$ & \\
\hline
\end{tabular}

${ }^{1}$ Mi: milho; Ve: vegetação espontânea; La: labe-labe; V1: $5 \mathrm{~km} \mathrm{hora-1}^{-1}$; V2: $7 \mathrm{~km}$ hora ${ }^{-1}$, médias seguidas pela mesma letra, maiúscula na coluna e minúscula na linha, em uma mesma classe de solo, não diferem entre si, a 5\% de probabilidade, pelo teste de Tukey.

Pela análise de variância, não foi verificada diferença significativa entre os espaçamentos médios ao variar a velocidade nos dois solos estudados e ao alterar o tipo de cobertura no Latossolo. O coeficiente de variação médio do espaçamento entre sementes no Latossolo foi de $61,81 \%$ e no Podzólico $63,51 \%$, indicando que houve grande variabilidade em torno do espaçamento médio. Os valores obtidos incluem-se na faixa obtida por Mantovani et al. (1992), da ordem de $50 \%$ a $87 \%$.

Segundo critérios adotados por Tourino \& Klingensteiner (1983), o desempenho da semeadoraadubadora no Latossolo pode ser considerado de regular a bom, conforme o tratamento. No Podzólico pode-se classificar o desempenho da semeadora- adubadora como bom (75\% a $90 \%)$ na velocidade de $5 \mathrm{~km}$ hora $^{-1}$, e regular (50\% a 75\%) na velocidade de $7 \mathrm{~km} \mathrm{hora}^{-1}$

\section{CONCLUSÕES}

1. A semeadora-adubadora apresenta índices de patinagem aceitáveis para o tipo de rodado apresentado e os valores de potência demandada pela máquina são inferiores aos indicados pelo fabricante, nas condições de solo e cobertura testadas.

2. A máquina testada apresenta boa regularidade na distribuição transversal e longitudinal de fertilizantes, e o número de sementes por hectare e o estande final não se mostram influenciados pela velocidade de trabalho e pelo tipo de cobertura. 
3. A qualidade das sementes distribuídas pela máquina não é afetada pelos mecanismos dosadores, comparando-se aos valores obtidos em relação às sementes que não passam pela máquina.

4. A profundidade média de plantio encontra-se bem próxima dos valores previstos na regulagem.

5. O desempenho da semeadora-adubadora pode ser caracterizado como bom na velocidade de $5 \mathrm{~km}$ hora $^{-1}$, e regular, a $7 \mathrm{~km}$ hora $^{-1}$.

\section{REFERÊNCIAS}

AMERICAN SOCIETY OF AGRICULTURAL ENGINEERS (Saint Joseph, Estados Unidos). ASAE standards 1990. Saint Joseph, 1990. 567p.

BALASTREIRE, L.A. Máquinas agrícolas. São Paulo : Manole, 1987. 307p.

DELAFOSSE, R.M. Máquinas semeadoras de grano grueso. Santiago : FAO, 1986. 48p.

EMBRAPA. Centro Nacional de Pesquisa de Trigo (Passo Fundo, RS). Avaliação do desempenho de plantadoras diretas para culturas de verão. Passo Fundo, 1994. não paginado.
EMBRAPA. Serviço Nacional de Levantamento e Conservação de Solos (Rio de Janeiro, RJ). Manual de métodos de análise do solo. Rio de Janeiro, 1979. não paginado.

KURACHI, S.A.H.; COSTA, J.A.S.; BERNARDI, J.A.; COELHO, J.L.D.; SILVEIRA, G.M. Avaliação tecnológica de semeadoras e/ou adubadoras: tratamento de dados de ensaios e regularidade de distribuição longitudinal. Bragantia, Campinas, v.48, n.2, p.249-262, 1989.

MANTOVANI, E.C.; BERTAUX, S.; ROCHA, F.E.C Avaliação da eficiência operacional de diferentes semeadoras-adubadoras de milho. Pesquisa Agropecuária Brasileira, Brasília, v.27, n.12, p.1579-1586, dez. 1992.

PACHECO, E.P. Avaliação de uma semeadoraadubadora de precisão com modificações no tubo condutor de sementes. Viçosa : UFV, 1994. 61p Dissertação de Mestrado.

TOURINO, M.C.; KLINGENSTEINER, P. Ensaio e avaliação de semeadoras-adubadoras. In: CONGRESSO BRASILEIRO DE ENGENHARIA AGRÍCOLA, 13., 1983, Rio de Janeiro. Anais. Rio de Janeiro : UFRRJ, 1983. v.2, p.103-116. 